\title{
Tardive dyskinesia update: the syndrome ${ }^{\dagger}$
}

\author{
David Cunningham Owens
}

\begin{abstract}
SUMMARY
Tardive dyskinesia is a common iatrogenic neurological and neurobehavioural syndrome associated with the use of antidopaminergic medication, especially antipsychotics. Prior to the introduction of the newer antipsychotics in the 1990s, it was one of the major areas of psychiatric research but interest waned as the new drugs were reputed to have a reduced liability to extrapyramidal adverse effects in general, a claim now discredited by numerous pragmatic research studies. Early small-scale short-term prevalence studies were presented as evidence to support the assumption that patients on the newer drugs did indeed have a lower prevalence of tardive dyskinesia but recent large-scale review of studies with patients exposed for longer suggest that things have not changed. This article presents a clinical overview of a complex and varied syndrome in terms of its phenomenology, epidemiology and risk factors; a companion article will consider treatment. This overview aims to highlight tardive dyskinesia once again, especially to practitioners who have trained in an environment where this was considered mainly in historical terms.
\end{abstract}

\section{LEARNING OBJECTIVES}

- Understand the complex phenomenology comprising the syndrome of tardive dyskinesia

- Appreciate recent data on prevalence and incidence with the newer antipsychotics

- Be aware of risk factors when recommending antipsychotic (and other antidopaminergic) drugs

\section{DECLARATION OF INTEREST}

None.

\section{Keywords}

Antipsychotics; tardive dyskinesia; prevalence; incidence; risk factors.

Psychiatry has never had a comfortable relationship with movement disorders. Parkinsonism, viewed since the 1960s as an adverse rather than an integral action of antipsychotics, a conditio sine qua non, has largely remained with neurology, whereas akathisia, long the orphan of psychiatric research, was adopted by sleep physicians, rebranded, and disconnected from its psychiatric roots.

Traditionally, psychiatry's interest was tardive dyskinesia (Fig. 1), a group of seemingly iatrogenic and potentially irreversible disorders that raised medico-legal considerations. A body of well-conducted long-term psychiatrically based research, funded independently of industry, emerged throughout the 1980s and early 1990s, solidifying the concept and expanding knowledge of its boundaries and correlates.

As this field was finding its scientific credentials it was dealt two blows. First, evidence suggested that relentless progression and irreversibility were not inevitable (Gardos 1994) and, with a degree of resolution possible, tardive dyskinesia could be accommodated within a risk-benefit appraisal for antipsychotics that was again acceptable. Second, and more important, new compounds arrived, fanfared as different in their pharmacology, with 'reduced EPS liability'. This was, on the face of it, a modest claim but to a demoralised profession starved of therapeutic innovation it was sufficient to make a fanciful leap: extrapyramidal side-effects (EPS) were no longer an issue. Tardive dyskinesia faded from the psychiatric literature, although Fig. 1 does not illustrate the extent of this decline. Neurology again took over as cases of drug-induced movement disorder in community patients came to tertiary specialists.

This indifference is dissipating. More detailed - and longer-term - evaluation of tardive dyskinesia with newer antipsychotics reveals a prevalence similar to that with older ones (Carbon 2017) and the first drugs specifically licensed for its treatment in the USA have come to market, with international promotion likely. It is therefore timely to present again the story of tardive dyskinesia to a generation of psychiatrists who may think this history. Tardive dyskinesia, like all EPS syndromes, is alive and well, living where it always has - comfortably within the pharmacology of all antipsychotic drugs.

\section{Origins and development of the concept}

The German psychiatrist Schonecker (1957) often gets credit for the first account but if priority appropriately rests with those who recognise novel implications, Jean Sigwald and colleagues from
David Cunningham Owens $\mathrm{MD}(\mathrm{Hons})$, FRCP, FRCPsych is professor of Clinical Psychiatry at the University of Edinburgh and an honorary consultant psychiatrist at the Royal Edinburgh Hospital, UK. He is also psychiatric commissioner on the Commission on Human Medicines (the UK drug regulator), chair of its expert advisory group on CNS drugs and a member of the psychiatry Scientific Advisory Group of the European Medicines Agency. A general adult psychiatrist, his longstanding interests lie in psychotic disorders, especially schizophrenia, and their treatment. His interest in drug-related movement disorders goes back to the 1970s and he is author of a textbook on the subject. Correspondence Professor David Cunningham Owens, University Division of Psychiatry, Kennedy Tower, Royal Edinburgh Hospital, Morningside Terrace, Edinburgh EH10 5HF, UK. Email: david.owens@ ed.ac.uk

\section{Copyright and usage}

(C) The Royal College of Psychiatrists 2018

${ }^{\dagger}$ A companion article by David Cunningham Owens will discuss the treatment and management of tardive dyskinesia 


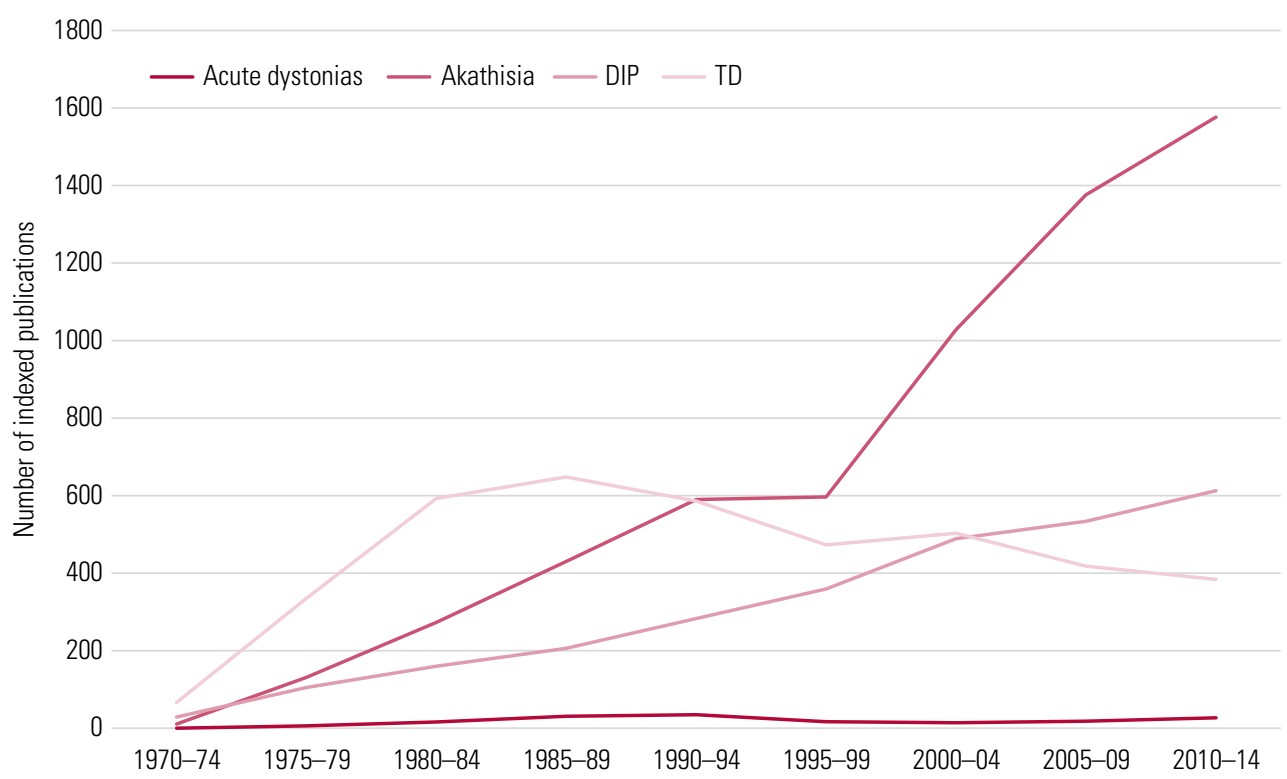

FIG 1 EPS syndromes: literature representation over time. DIP, drug-induced Parkinsonism; TD, tardive dyskinesia. Data from PubMed search.

France better fulfil that requirement (Sigwald 1959). It was, however, the Danes, Uhrbrand and Faurbye (1960), who brought the condition to life.

The term tardive dyskinesia subsequently appeared in an overview of neurological features associated with antipsychotic use (Faurbye 1964). Descriptively, the concept seemed straightforward. Although 'tardive' literally means 'arriving/coming late', it carries a relative implication. The inference is not of a specific time criterion but of onset later than the other neurological adverse reactions of the class. This clearly left potential for variability, which Faurbye and colleagues addressed by suggesting at least 6 months of antipsychotic exposure as a time criterion (Faurbye 1964). The literature tended to greater conservatism - a year or two minimum (Ayd 1967) - while still presenting putative cases with exposure of weeks or even days (Chouinard 1979). The generality of 'later' could not be squeezed into fixed temporal boundaries.

'Dyskinesia', not a word with wide prior usage, generically means 'any abnormal kinesis'. For this syndromal use, it was restricted to abnormal hyperkinetic movements with 'co-ordinated, involuntary, stereotyped, rhythmic' characteristics (Faurbye 1964), predominantly targeted on the mouth, although these helpful adjectives relating to form hid a problem that only emerged later. For those neurologists who shared an early interest in this field with psychiatrists, the presentation had mixed characteristics that recalled movements they knew well - chorea and athetosis. These perioral signs were therefore universally referred to as 'choreoathetoid' (Marsden 1986) and regarded as authentically 'involuntary'. However, they were also complex and, as Faurbye et al pointed out, coordinated. These were not in themselves abnormal movements but seemed appropriate oromandibular behaviours that lacked context, such as eating. It was 'as if the entire template for a set of complex conditioned behaviours is laid vulnerable to release from tonic inhibition' (Owens 2014).

In the mid-1990s, neurologists began to focus on Faurbye et al's third descriptor, referring to the oromandibular component as 'tardive stereotypies'. This settled one problem - the predominant component was not choreoathetoid - but in the absence of a consensus on what 'stereotypy' meant (Ridley 1994; Edwards 2012), opened another. Much, though not all, of what is overt in tardive dyskinesia may be 'unwilled' but it is not 'involuntary'.

A further debate of historical relevance was fundamental - did tardive dyskinesia actually exist? This argument is too far-reaching to present here (for discussion see Owens 2014) but while schizophrenia can itself be associated with motor disorder, the significance to those on antidopaminergics remains unclear. Neither, however, does this distract from the undoubted validity of tardive dyskinesia as a syndrome construct.

In essence, tardive dyskinesia is what clinicians and authors believe it to be (Owens 2014). This is not to be over-cynical. The point is that, in considering a differential diagnosis, this disorder - so unpredictable in onset, so phenomenologically varied - is best conceptualised in terms of its inference, and that is clear. Tardive dyskinesia is any hyperkinetic motor disorder (except tremor) in which drugs, especially although not exclusively antidopaminergics, are believed to play a causative role. 


\begin{tabular}{|c|c|c|c|}
\hline Chorea & Movement & $\begin{array}{l}\text { Rapid (brief) } \\
\text { Rudimentary } \\
\text { Non-rhythmic } \\
\text { Non-recurrent } \\
\text { Involuntary }\end{array}$ & ‘Dancing' \\
\hline Athetosis/dystonia & Movement & $\begin{array}{l}\text { Slow(er)-sustained } \\
\text { (More) complex (may involve multiple muscle groups) } \\
\text { Non-rhythmic } \\
\text { Recurrent } \\
\text { Involuntary }\end{array}$ & 'Writhing' \\
\hline Choreoathetosis & Movement & Combination of chorea and athetosis & \\
\hline Stereotypies & (Neuro-)behaviour & $\begin{array}{l}\text { No definitional consensus } \\
\text { 'Repetitive, unvarying, functionless behaviour' (Ridley 1994) } \\
\text { 'Non-goal directed movement pattern repeated continuously in the same form [...] } \\
\text { typically distractible' (Edwards 2012) } \\
\text { Complex } \\
\text { Coordinated } \\
\text { Suppressible } \\
\text { Sudden (explosive) } \\
\text { Recurrent }\end{array}$ & Acontextual \\
\hline Tics & (Neuro-)behaviour & $\begin{array}{l}\text { Complex } \\
\text { Non-rhythmic }\end{array}$ & Suppressible, yet irresistible \\
\hline Myoclonus & Movement & $\begin{array}{l}\text { Ultra-rapid/sudden } \\
\text { Brief } \\
\text { Recurrent } \\
\text { Rudimentary to complex Involuntary }\end{array}$ & Twitches, jerks \\
\hline
\end{tabular}

\section{Clinical features}

\section{Core abnormalities}

Traditionally, tardive dyskinesia has been a blanket term encompassing the range of hyperkinetic disorders, except tremor (Box 1). These comprise both movements that are clearly involuntary and more complex abnormalities, best considered 'neurobehavioural', which span the voluntary/involuntary divide. Tics, for example, like acute akathisia, are preceded by an urge to activate in a way that is 'suppressible yet irresistible' (Dure 2006).

\section{Signs}

Tardive dyskinesia can affect any voluntary muscle and an elementary but important point is that, as a syndrome, can create kaleidoscopic presentations from diverse constituents (Table 1). The sheer range and combinations of movement types contribute greatly to confusion inherent to categorisation and diagnosis.

\section{Orofacial}

Clinically, distribution is an invaluable aid to diagnosis (Fig. 2). In $80 \%$ of cases, especially at the milder end, disorder is found in the lower third of the face. Clinical experience suggests this, too, may comprise different components.

Disorder has always been thought of as starting with the tongue, although this has never been confirmed. The author has certainly seen patients in whom other movements were gross but tongue abnormality minimal or absent. These early signs are usually described as vermicular (worm-like) and in the tongue. In the early stages individual parts of the tongue's surface can be seen to move, with progression, turning it into a 'bag of worms'. The structure itself, however, is not strikingly displaced, remaining within the floor of the mouth. Displacement becomes evident with progression, when activity causes curling along its transverse axis, arching and/or rotation on its longitudinal axis or lateral movement, in more severe instances sweeping inner surfaces, especially of the cheeks ('bon-bon' sign) and sometimes the lips, usually the lower lip. Protrusion beyond parted lips can be central or to one side and may be slow and rhythmic, or darting ('fly-catcher' sign). Mouth-opening, forced jaw closure, bruxism, lateral jaw deviation and a range of lip movements, including puckering, pouting, smacking and bridling (retraction of the angles of the mouth), with or without accompanying sounds, complete a characteristic picture. 
TABLE 1 Tardive dyskinesia: major clinical signs

\begin{tabular}{|c|c|c|c|}
\hline Musculature & Central/orofacial & Musculature & Peripheral \\
\hline Tongue & $\begin{array}{l}\text { Within dental margin } \\
\text { 'Vermicular' movements (no displacement) } \\
\text { Displacement on one or more axes } \\
\text { Beyond dental margin } \\
\text { 'Sweeping' (buccal/lips) } \\
\text { Irregular non-recurrent protrusion }\end{array}$ & Axial & $\begin{array}{l}\text { Head/neck/trunk } \\
\text { Torti-/antero-/retro-/latero-collis } \\
\text { Anteroposterior/lateral displacement (Pisa syndrome) } \\
\text { Shoulder shrugging } \\
\text { Axial hyperkinesis ('copulatory') } \\
\text { Tics/tic-like movements }\end{array}$ \\
\hline Jaw & $\begin{array}{l}\text { Opening plus opening/closing } \\
\text { Lateral deviation } \\
\text { Anterior protrusion } \\
\text { Chewing } \\
\text { Bruxism (grinding) }\end{array}$ & Upper limbs & $\begin{array}{l}\text { Hyperpronation } \\
\text { Wrist/elbow flexion/extension } \\
\text { Metacarpophalangeal } \\
\text { Flexion/extension ('piano-playing') } \\
\text { Finger filliping } \\
\text { Lateral out-splaying } \\
\text { Exaggerated/distorted arm swing }\end{array}$ \\
\hline Lips & Pursing, puckering, sucking, smacking, angular, retraction & Lower limbs & $\begin{array}{l}\text { Abduction/adduction } \\
\text { Flexion/extension (hips/knees/ankles) } \\
\text { Ankle rotation inversion/eversion of foot } \\
\text { Lateral out-splaying/flex/extension of toes Gait disturbance }\end{array}$ \\
\hline Expression & $\begin{array}{l}\text { Blepharoclonus/spasm } \\
\text { Elevation/depression of eyebrows } \\
\text { Forehead furrowing } \\
\text { Grimacing } \\
\text { Conjugate eye deviation (oculogyrus) }\end{array}$ & Internal & $\begin{array}{l}\text { Dysphagia } \\
\text { Dyspnoea/audible respirations } \\
\text { Spontaneous vocalisations } \\
\text { Speech disorders } \\
\text { Dysarthria } \\
\text { Irregular phrasing } \\
\text { Nasal/staccato/breathless speech }\end{array}$ \\
\hline
\end{tabular}

Some of this activity seems choreoathetoid and authentically involuntary. However, in the more extravagant activity, such as buccal sweeping and chewing, we see the basis of complex behaviours, where intra-oral activity is coordinated with lips and jaws. The combination of complex, oralfocused disorder has traditionally been referred to as the bucco-linguo-masticatory (BLM) triad, although the buccal component is a passive participant compared with the often active involvement of lips, and the triad might better be described as labio-linguo-masticatory (Owens 2014).

Only one study (Glazer 1988) supports the author's impression that two different phenomenologies comprise the oral component of tardive dyskinesia: one, authentically involuntary and of choreoathetoid type, predominantly localised to the tongue but with the potential to involve jaw and lips; the other, a coordinated pattern of 'release' conditioned behaviours related to normal oromandibular/lingual activity in the preparation of food for swallowing. However, such a distinction could explain why patients frequently seem unaware of often disfiguring disorder. This observation, much commented on (Alexopoulos 1979; McPherson 1992; Sandyk 1993), is in contradistinction to other EPS syndromes (Owens 2014) but may be understandable if relevant to automatic behaviours as opposed to genuinely involuntary movements. In the author's experience, patients with dominant independent tongue activity are very poorly tolerant of what is both annoying and, because of local irritation, sometimes uncomfortable, whereas those with complex oromandibular activity which, because it is coordinated does not isolate the tongue or subject it to injury (although it may stimulate hypertrophy), are more likely to be indifferent.

Breaking down motor disorders phenomenologically has merit in demonstrating the rich disorder tardive dyskinesia presents but does introduce an element of artificiality. Forced tongue protrusion clearly requires the lips, and in those with teeth the jaws, to part. So, when are these separate components or part of a package? Many such examples arise when recording with multi-item, as opposed to global impression, rating scales (Owens 2014).

Tics may rarely affect the upper face but more commonly movements here are choreiform or dystonic and genuinely involuntary. Involvement of eyelids, periocular and temporal musculature gives rise to blepharoclonus, partial or complete blepharospasm, frowning, furrowing, grimacing, etc. Marked upper face involvement produces especially disfiguring disorder.

\section{Peripheral}

In $20 \%$ of cases, distribution is predominantly trunk and/or limbs, although peripheral disorder may develop in combination with orofacial abnormality. 


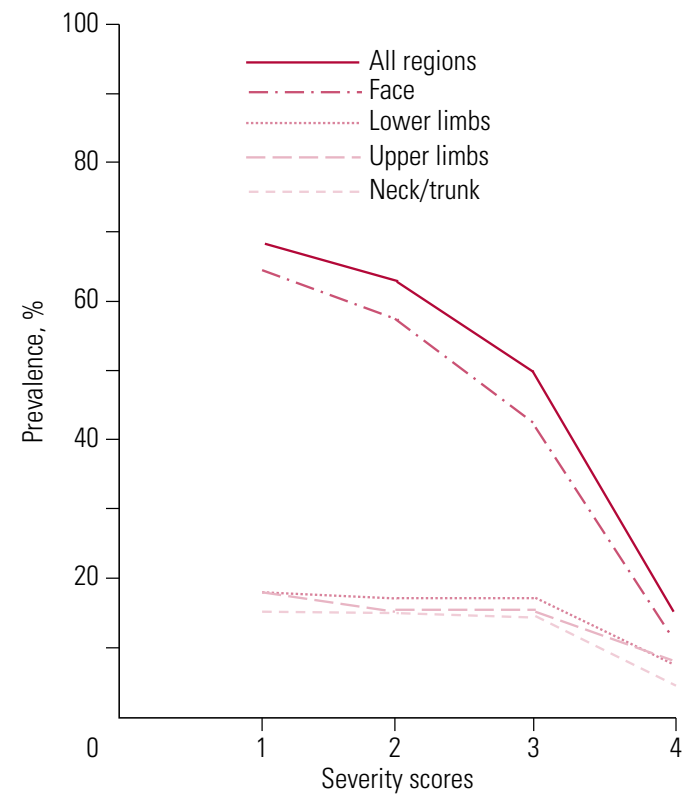

FIG 2

Prevalences of movement disorders in different body regions at different severity scores on the Abnormal Involuntary Movement Scale (AIMS) (Owens 1982).

With the exception of tics (which are relatively uncommon), peripheral disorder is characteristically involuntary and dystonic in type, with sustained (static) or kinetic attitudinal changes in the head/ neck and limbs and/or postural distortions of the trunk. Torticollis is often best spotted from behind, in the compensatory kyphoscoliosis evident on walking, where the shoulder on the side of the turn is raised and promoted forward, or by the presence of antagonistic gestures (touching/pressing/massaging the opposite side of the neck to relieve the extent or discomfort of the displacement). Involvement of the upper limb girdle produces irregular shoulder shrugging or rotations, and of pelvic musculature, so-called copulatory movements. Arms may pronate, fingers show lateral out-splaying or flexion/extension piano-playing movements. Legs may likewise rotate, with intermittent, sustained rotational movements of ankles and out-splaying of toes. The lateral truncal leans, usually associated with slight rotation, of Pisa (or Ekbom) syndrome are rare as the sole abnormality but can seriously impede mobility. Peripheral disorder centred on lower limbs can be hard to distinguish from tardive akathisia.

Internal voluntary muscles of the oropharynx, larynx and diaphragm can also be involved in tardive changes, resulting in some of the most medically concerning complications, such as dysphagia (with or without inhalation), stridor and speech distortions (laryngeal adductor or abductor spasms), along with less sinister hiccups, grunts and groans from intercostal or diaphragmatic involvement.

Words cannot adequately describe the varied and intricate presentations of tardive dyskinesia, and inability to categorise all aspects of its component parts should not unnerve the generalist. The important point is to be sensitive enough to this variability to recognise when iatrogenic disorder is taking root without misattributing it.

\section{Subtypes}

Tardive dyskinesia may come on during drug exposure (treatment-emergent) or following discontinuation or dose reduction (withdrawal-emergent). Sometimes the latter type persists but withdrawalemergent disorder is, overall, more likely to resolve and is the most common presentation in children (Owens 2014). Resolution usually occurs over a couple of weeks but may take months.

In some instances, dystonia is the predominant or exclusive abnormality and in such cases a diagnosis of tardive dystonia is appropriate. This distinction is important as tardive dystonia is much more functionally incapacitating than generic tardive dyskinesia, especially if that term is restricted to perioral disorder, and may have different treatment and other characteristics. Clinically, a classification based on how prominent dystonia is to the overall presentation can be useful in treatment planning (Adityanjee 1999) (Box 2).

Rarely, tics form the greater part of the presentation and, again, separate consideration is justified. Only a handful of cases of tardive Tourette syndrome have appeared in the literature but they are worth knowing about as they can be among the most dramatic tardive dyskinesia presentations of all.

Analysis of rating scale data consistently shows at least two components to tardive dyskinesia - perioral, most strongly associated with age, and limb/ truncal, more directly attributable to drug factors (e.g. Kidger 1980; Glazer 1988; Gureje 1989). In

\section{BOX 2 Subdivision of tardive dystonia}

Type 1 Pure dystonia: no other movement disorder type

Type 2 Coexisting dyskinetic movements in same or different body part(s), but dystonia predominates

Type 3 Coexisting dyskinetic movements in same or different body part(s) more prominent than dystonia

Type 4 Part of a mixed picture: coexisting Parkinsonism, akathisia, etc. with no one predominating (Adityanjee et al, 1999) 
line with the view presented above, Glazer et al (1988) found that orofacial disorder itself comprised two components, although 'jaw-tongue' and 'face-lips' are not entirely consonant with my experience. Nonetheless, data supporting distributional differences are sufficiently robust that assessment of interventions should take them into account.

\section{Recent trends in classification}

The concept of tardive dyskinesia has undergone expansion and contraction over the years, initially including what would become akathisia (Faurbye 1964), which was subsequently stripped out, although the most common movement disorder, tremor, was always specifically excluded (Marsden 1975). Recently, neurologists have proposed subclassification of all tardive presentations under the single rubric of 'tardive syndrome' (Frei 2018), where the core concept is not later onset but persistence (Box 3). This is justified on the basis of varied phenomenologies.

In this system, tardive dyskinesia refers to 'classical oro-buccal-lingual dyskinesia' but also comprises 'choreic movements in other body parts', although tardive stereotypy 'fails to fulfil the definition of stereotypy' (Aquino 2014), so is somewhat left in the air! Tardive akathisia, having started life as a discrete entity, becomes subsumed within the generality of tardive dyskinesia. A tardive gait, described as 'dancing' or 'duck-like', is proposed as 'a new entity' (Kuo 2008), while so-called tardive tremor is also incorporated. Tardive Parkinsonism is, furthermore, considered legitimate by some.

Simplicity might justify such changes but phenomenology does not necessarily correlate sufficiently with pathophysiology to support the validity of cross-sectional, clinically led micro-classification. It seems peculiar to lump together all oromandibular

BOX 3 Tardive syndrome

Encompassing

- Tardive dyskinesia (oro-buccal-lingual, plus choreiform movements in any other body parts)

- Tardive stereotypy

- Tardive akathisia

- Tardive dystonia

- Tardive myoclonus

- Tardive tremor

- Tardive tics (Tourette-like)

- Tardive pain (chronic oral/genital pain/dysaesthesia)

- Withdrawal-emergent dyskinesia

(Aquino 2014) with peripheral disorder when, as noted, multivariate analysis of rating scale data consistently suggests a syndrome of at least two components, and the question of whether tardive akathisia has pathophysiologically more in common with akathisia or tardive dyskinesia was much debated (Munetz 1982; Barnes 1985; Dufresne 1988) but never answered. As the psychiatric literature shows, gait disorders can be striking in tardive dyskinesia but the merit of considering them a discrete new entity is questionable, while tardive tremor is exceedingly rare (Ure 2016; Frei 2018) and of doubtful relevance to the long-established tardive dyskinesia concept. Finally, the notion of tardive parkinsonism (Melamed 1991) seems contemplatable only when the prolonged binding characteristics of high-potency dopamine $\mathrm{D}_{2}$ receptor blockers and the revealing effect of drugs on idiopathic disease are overlooked (Owens 2014).

One innovation within this system is the highlighting of 'tardive pain' (Frei 2018). While conventional pain is a frequent accompaniment of tardive, especially craniocervical, dystonia, sometimes discomfort in the mouth seems disproportionate. Furthermore, the author has encountered a small but memorable group of patients, usually female, with bizarre complaints - more dysaesthesia than pain and usually genitally focused - that at the time the author never associated with tardive dyskinesia. This may not arise often but occasionally may be diagnostically illuminating.

For psychiatrists who deal daily - and, mostimportantly, prospectively - with the consequences of longterm antipsychotic use, the traditional concept of tardive dyskinesia, defined in terms of movement types and distribution, is best retained until alternatives can demonstrate utility and validity.

\section{Differential diagnoses and diagnostic criteria}

There is always a differential diagnosis in someone presenting with new-onset movement disorder and this can be extensive (Table 2). A similar pattern of predominantly oromandibular disorder can develop in older individuals, formerly referred to as senile chorea but more accurately called simply spontaneous dyskinesias. Likewise, $16 \%$ of edentulous individuals can be similarly afflicted, where disorder may result from loss of proprioceptive input from dental apices (Koller 1983). These states have been poorly studied, although in psychiatric cohorts, data suggest a much lower prevalence $(2.6 \%)$ in the unimpaired elderly than similarly appearing movements in those on antidopaminergic medication (Woerner 1991). In younger patients with untreated schizophrenia the relationship 


\begin{tabular}{|c|c|}
\hline Brain pathology: aetiological type & Examples \\
\hline Hereditary & $\begin{array}{l}\text { Huntington's disease } \\
\text { Wilson's disease } \\
\text { Dystonia musculorum deformans }\end{array}$ \\
\hline Degenerative & $\begin{array}{l}\text { Senile chorea } \\
\text { Parkinson's disease (especially with L-dopa treatment) }\end{array}$ \\
\hline Infective & $\begin{array}{l}\text { Sydenham's chorea } \\
\text { HIV/AIDS } \\
\text { Variant Creutzfeldt-Jakob disease }\end{array}$ \\
\hline Immune & $\begin{array}{l}\text { Multiple sclerosis } \\
\text { Systemic lupus erythematosus }\end{array}$ \\
\hline Traumatic & $\begin{array}{l}\text { Closed head injury } \\
\text { Haemorrhage (subdural/extradural) }\end{array}$ \\
\hline Neoplastic & Primary/secondary tumour \\
\hline Metabolic & $\begin{array}{l}\text { Hyperthyroidism } \\
\text { Hypoparathyroidism } \\
\text { Hyperglycaemia/hypoglycaemia }\end{array}$ \\
\hline Toxic & $\begin{array}{l}\text { Withdrawal (alcohol) } \\
\text { Substance misuse } \\
\text { Heavy metals }\end{array}$ \\
\hline Vascular & $\begin{array}{l}\text { Infarction } \\
\text { Arteriovenous malformation }\end{array}$ \\
\hline Miscellaneous & $\begin{array}{l}\text { Edentulous oromandibular dyskinesia } \\
\text { Migraine } \\
\text { Pregnancy (chorea gravidarum) }\end{array}$ \\
\hline
\end{tabular}

between spontaneous dyskinesias and a range of apparently involuntary movements that seem indistinguishable from tardive dyskinesia (Owens 1982; McCreadie 1996) is also unclear.

Having reassured oneself of the validity of the diagnosis, it is useful, even in routine practice, to apply standardised diagnostic criteria, the most widely utilised being those of Schooler $\&$ Kane (1982) (Box 4). This is less about diagnosis, which should be established clinically, but allows for monitoring progression, persistence etc. and can contribute to prognostication.

\section{Epidemiology}

After a shaky start, the tardive dyskinesia literature covering the period of older antipsychotics produced a body of quality research, funded independently of industry, relating to prevalence, incidence and risk factors. No comparable research base exists for the newer, so-called atypical drugs but as no evidence has emerged to support the hope that (with the sole exception of clozapine) these drugs differ sufficiently in their pharmacology to affect the epidemiology of tardive dyskinesia, it is legitimate to present what we knew then as what we ought to know now.

It is important to realise that, owing to the intimate relationship all EPS syndromes bear to practice principles (how drugs are used), there is no such thing as the prevalence, incidence, etc. - only what is relevant to how antipsychotics are/were used there and then.

\section{Prevalence}

By the late 1980s/early 1990s there was concurrence that the point prevalence of tardive dyskinesia was $20 \%$ in chronically treated samples in both the USA (Woerner 1991) and Europe (Muscettola 1993). Individuals were defined by Schooler and Kane criteria, implying more than one examination, which likely lowers overall prevalence as it removes patients with mild or equivocal signs. Nonetheless, this corresponds well to the less impressive literature

BOX 4 Tardive dyskinesia: the Schooler and Kane criteria

\section{A. Prerequisites}

1 Minimum 3 months cumulative antipsychotic exposure (continuous or discontinuous)

2 Abnormal movements at least 'moderate' in one body part or 'mild' in two or more (standardised rating)

3 No other potential cause

\section{B. Diagnoses}

(a) Probable: Fulfils 1-3 on a single examination

(b) Masked probable: Fulfils 1-3 at first examination but fails on 2 above on second examination within 2 weeks of drug increment or reintroduction (c) Transient: Fulfils 1-3 at first examination but fails on 2 above on second examination within 3 months with no increase or reintroduction of drug (reduction possible)

(d) Withdrawal: Does not fulfil 2 while on medication but fulfils $1-3$ within 2 weeks of stopping drugs of average halflife or 5 weeks with long half-life preparations (e.g. depots)

(e) Persistent: Fulfils $1-3$ at first examination and over at least a subsequent 3-month period

(f) Masked persistent: As (e) but fails to fulfil 2 with 3 weeks of dose increment or reintroduction

(Schooler \& Kane, 1982) 
TABLE 3 Estimated risk (\%) of persistent tardive dyskinesia in the context of prior exposure

\begin{tabular}{|llllll|}
\hline $\begin{array}{l}\text { Years of prior exposure } \\
\text { without developing tardive } \\
\text { dyskinesia }\end{array}$ & \multicolumn{6}{l}{ Additional years of exposure } \\
\cline { 2 - 6 } & $\mathbf{5}$ & $\mathbf{1 0}$ & $\mathbf{1 5}$ & $\mathbf{2 0}$ & $\mathbf{2 5}$ \\
\hline 0 & 32.7 & 45.8 & 53.8 & 60.2 & 64.7 \\
5 & 19.4 & 31.3 & 40.9 & 47.6 & \\
10 & 14.2 & 26.7 & 35 & & \\
15 & 14.0 & 23.7 & & \\
20 & 11.3 & & & \\
\hline
\end{tabular}

Source: data from Glazer et al (1993). antipsychotic exposure, permitted calculation of the long-term risk of tardive dyskinesia emerging in those who remained free of disorder for increasingly longer periods of time. These projections (Table 3) showed that the risk never really disappears. Even after two decades of uneventful antipsychotic treatment, the risk with continued exposure is still around $10 \%$ over the subsequent 5 years.

A further important finding from the Hillside group is that risk over time is not linear. Incidence accelerates in the second 6 months of exposure, with only gradual increment thereafter until a further 'jump' early in the fifth year (Chakos 1996). That most of this is mild/moderate disorder leaves the possibility that relationships with risk are log-dose ones, where risk plateaus above moderate doses (Tarsy 2006), which is both theoretically and clinically plausible. unrelated and spontaneous movements be inevitable. It seems reasonable to conclude that the prevalence of tardive dyskinesia remains at 20\%.

The modern literature is of insufficient quality to allow comment on severity (Carbon 2017) but these worrying figures are tempered by the fact that most abnormality in point/period prevalence tardive dyskinesia studies is of mild severity, usually requiring specific examination to elicit. In one study, only $43 \%$ of those affected were rated as moderate or moderately severe at follow-up and none was rated severe (Kane 1988). Severe tardive dyskinesia is the exception.

\section{Incidence}

Two prospective US studies found cumulative annual incidences of 5\% for persistent disorder: the Hillside study (Kane 1982) and the Yale study (Morgenstern 1993). The Hillside (New York) study comprised diagnostically heterogeneous patients, mainly treated with high-potency compounds but the same group subsequently followed up patients with first-episode schizophrenia and confirmed a cumulative incidence of $4.8 \%$ at 1 year and $15.6 \%$ at 4 years (Chakos 1996). The exceptionally long follow-up of the original Hillside sample allowed confirmation of a fact for many years viewed sceptically. Early cross-sectional assessments of predominantly institutional patients reported prevalences of over 50\% (Owens 1982). Hillside data found a cumulative figure of $52 \%$ over 15 years, again mostly of mild disorder (Fig. 2). However, by the late 1980s amber flags were flying.

Concern was emphasised by projections from the Yale study (Glazer 1993). One of the many frustrations of tardive dyskinesia is its apparently random occurrence in patients otherwise asymptomatic for years. The Yale study, focusing on schizophrenia, reported a 5-year incidence of 5.3\% (Morgenstern 1993) but because of variable durations of

\section{Risk factors}

A great deal of effort went into establishing risk factors for tardive dyskinesia. The older literature was largely retrospective and blighted by the flaws of such approaches. Nonetheless, there is some consistency between what it suggested and factors identified from later, largely prospective data. Box 5 presents a composite of those factors shared across both designs (for details, see Owens 2014).

\section{Age}

The most consistent factor predisposing to the development of tardive dyskinesia is age - the older the patient the greater the risk. It is likely that age operates independently of duration of illness and exposure, as annual incidence is much greater (up to six-fold) in those first exposed to antipsychotics Furthermore, in elderly patients the cumulative incidence of orofacial disorder is twice that of peripheral disorder (Paulson 1996), supporting the idea that

BOX 5 Tardive dyskinesia: predisposing factors

The following predisposing factors are evident in both retrospective and prospective literatures:

- Age

- Antipsychotic potency

- Antipsychotic-free intervals (number)

- Previous (early) extrapyramidal symptoms

- Affective disorders

- Organicity: leucotomy, structural brain change, negative (deficit) symptoms

- Genetics (From Owens 2014) in middle to late life (Jeste 1995, 2000). 
antipsychotics may in part be bringing forward focal, age-related changes.

\section{Antipsychotic variables}

Neat correlations with antipsychotic drug variables (daily dose, duration of exposure, cumulative exposure, potency, polypharmacy), which seem obvious, proved hard to pin down, although this is hardly surprising. Not only is it unlikely that associations are linear, the pharmacokinetics of antipsychotics are so variable across individuals as to introduce a major obstacle to establishing risk relationships. However, in general, prospective data do suggest that the more antipsychotic a patient receives, in terms of daily exposure - especially as reflected in potency - more than duration, the greater the likelihood of tardive dyskinesia. In the Yale study, the risk was 2.5 times greater in those receiving $500 \mathrm{mg} /$ day chlorpromazine equivalent (CPZeq) antipsychotic than those on $100 \mathrm{mg}$ CPZeq or less (Morgenstern 1993), and the Hillside study, although establishing only a trend significance for dose overall, reported that each $100 \mathrm{mg}$ CPZeq dose increase was associated with a 5\% increase in at least 'presumptive' disorder (Chakos 1996). This emphasises that, for tardive dyskinesia risk, what we consider standard doses are sufficient to sow the seeds of dopaminergic disruption.

\section{Drug-free intervals}

One unexpected finding from the older literature was an association with drug-free intervals. This was at a time when 'drug holidays' were widely advocated to diminish exposure and hence risk but the best discriminator between 'reversible' and 'persistent' tardive dyskinesia was the greater number of periods, 2 months or longer, the latter group experienced off antipsychotic (Jeste 1979). This was replicated with off intervals as short as 1 month and supported prospectively (Branchey 1984; Chakos 1996). The risk of tardive dyskinesia may increase as much as threefold with upwards of three interruptions to treatment (van Harten 1998). This is important for clinicians - and patients - to appreciate. It is better to decide early in relapsing-remitting illnesses what 'long-term' medication recommendations actually mean.

\section{Pre-existing neurological problems}

Logically, those who develop long-term neurological problems would most likely be those who experienced neurological issues earlier in treatment, although this again took time to emerge (DeVeaugh-Geiss 1982). In general, the literature supports an association, especially with prior akathisia in older patients. Woerner et al (1998) found a cumulative tardive dyskinesia incidence of $26 \%$ in those without akathisia that inflated to $71 \%$ if akathisia had been present earlier. Nonetheless, while a similar increase in tardive dyskinesia risk (twofold) was found in the Schizophrenia Outpatient Health Outcomes (SOHO) study over only 12 months (Tenback 2006), its authors found 'acute-end' EPS to be a weak predictor of later tardive dyskinesia. One obvious problem is the composite nature of acute-end EPS, which may comprise disorders with sufficient pathophysiological variability to invalidate lumping them together. A single report, relating to newer antipsychotics, supports the intuitive belief that acute dystonias predispose to tardive dystonia (Ryu 2015).

\section{Mood disorders}

There is a long-reported association between increased tardive dyskinesia risk and mood disorders, which extends to newer drugs (Gardos 1984). This creates an obvious paradox: if schizophrenia is associated with an inherent risk of movement disorders, why is the risk of tardive dyskinesia greater in those with mood disorders? Although replicated, this may be a confounded observation (Owens 2014), the most obvious reason being that those with mood disorders are more likely to experience intermittent antipsychotic exposure.

\section{Damaged neural substrate}

A further association with face validity is that vulnerability may result from a damaged brain substrate. A wide range of parameters reflecting organic brain change, both primary and secondary to psychiatric disorder, have been evaluated and, although positive relationships have emerged, the association remains weak and general (Owens 2014).

\section{Genetic predisposition}

Since not everyone at risk (i.e. exposed) develops tardive dyskinesia, liability has long been put down to individual susceptibility. While any one, or combination, of the above risks might constitute predisposition, by far the most likely factor(s) underlying individual susceptibility are genetic. These fall into two broad categories - mutations that directly predispose regardless of drug exposure (e.g. receptor/ signalling proteins; enzymes) and those that predispose by altering exposure itself (e.g. pharmacokinetics) (Tables 4 and 5).

It is beyond my present remit to review the relevant genetic literature and interested readers are referred to specialist publications (MacNeil 2016). It is fair to say, however, that the situation has not advanced substantially since I concluded, on the basis of data up to 2012, that "work to date does 
TABLE 4 Tardive dyskinesia: negative or unreplicated gene mutations suggested as predisposing

\begin{tabular}{|c|c|c|}
\hline Candidate & Protein & Gene \\
\hline Dopamine & $\mathrm{D}_{4}$ receptor & DRD4 \\
\hline Adenosine & Adenosine $\mathrm{A}_{2 \mathrm{~A}}$ receptor & ADORA2A \\
\hline Serotonin $(5-\mathrm{HT})$ & 5- $\mathrm{HT}_{2 \mathrm{C}}$ receptor & HTR2C \\
\hline Gamma-aminobutyric acid & $\begin{array}{l}\mathrm{GABA}_{A} \text { receptor } \beta-2 \text { subunit } \\
\mathrm{GABA}_{A} \text { receptor } \gamma-3 \text { subunit } \\
\text { GABA transporter } 3\end{array}$ & $\begin{array}{l}\text { GABRB2 } \\
\text { GABRG3 } \\
\text { SLC6A11 }\end{array}$ \\
\hline Cannabinoid & CB1 receptor & CNR1 \\
\hline Oxidative stress/metabolism & $\begin{array}{l}\text { Manganese superoxide dismutase } \\
\text { Endothelial nitric oxide synthase } \\
\text { NAD(P)H:quinone oxidoreductase } \\
\text { Glutathione S-transferase } \mu>1 \\
\text { Glycogen synthase kinase } 3-\beta \\
\text { Dipeptidyl aminopeptidase-like protein } 6\end{array}$ & $\begin{array}{l}\text { MnSOD } \\
\text { NOS3 } \\
\text { NOO1 } \\
\text { GSTM1 } \\
\text { GSK3B } \\
\text { DPP6 }\end{array}$ \\
\hline Signalling cascades & $\begin{array}{l}\text { Regulator of G-protein signalling } 9 \\
\text { Arrestin } \beta-2 \\
\text { Tumour necrosis factor alpha }\end{array}$ & $\begin{array}{l}\text { RGS9 } \\
\text { ARRB2 } \\
\text { TNFA }\end{array}$ \\
\hline Developmental/plasticity factors & $\begin{array}{l}\text { GLI family zinc finger protein } 2 \\
\text { NMDA receptor subunit } 2 \mathrm{~A} \\
\text { NMDA receptor subunits } 2 \mathrm{~B} \\
\text { Brain-derived neurotrophic factor }\end{array}$ & $\begin{array}{l}\text { GLI2 } \\
\text { GRIN2A } \\
\text { GRIN2B } \\
\text { BDNF }\end{array}$ \\
\hline CYP isoenzymes & CYP450 1A2 & CYP1A2 \\
\hline
\end{tabular}

Source: Owens (2014)
Much of this work explores theoretically obvious candidates, such as dopamine receptor genes and those of systems known to modify dopaminergic function (serotonin, adenosine, GABA, cannabinoid, etc.), although more recently genome-wide association studies (GWAS) have emerged. Results from either method thus far point at best to marginal effects, at worst to statistically artefactual, incidental findings.

The most statistically robust (though still weak) effects relate to cytochrome P450 (CYP450) genotypes (Table 5). Because of their metabolic requirements (hydroxylation/demethylation/dealkylation) many psychotropic compounds are particularly dependent on the highly polymorphic CYP2D6. Although susceptible to inhibition, unusually, 2D6 is resistant to induction, so the impact of polymorphisms on overall metabolic capability can be strikingly magnified. Focusing on just 7 prospective studies (from a mixed group of 20), Fleeman et al (2010) found a significant reduction in tardive dyskinesia ratings in extensive metabolisers, compared with intermediate and poor metabolisers - i.e. those with two functioning wild-type (wt) alleles were relatively spared compared with those with one or two non-functioning or poorly functioning mutant (mut) alleles respectively. Genotyping 2D6 is easy, relatively inexpensive and commercially available, although currently evidence is insufficient to justify routine testing prior to commencing long-term

antipsychotics. not point to a clear, single abnormality that might provide a key to unlocking "the" genetic predisposition to tardive dyskinesia at the receptor, enzyme or kinetic levels' (Owens 2014).

TABLE 5 Tardive dyskinesia: replicated gene mutations suggested as predisposing ${ }^{a}$

\begin{tabular}{|c|c|c|c|c|c|}
\hline Candidate & Protein & Gene & SNP & Reviews & Significance, OR \\
\hline \multirow[t]{3}{*}{ Dopamine } & $\mathrm{D}_{2}$ receptor & DRD2 & Taq1A (rs1800497) & 2 (10 studies) & $\begin{array}{l}1.30 \text { (Zai et al, 2007) } \\
\quad 1.30 \text { (Bakker et al, 2008) }\end{array}$ \\
\hline & $\mathrm{D}_{3}$ receptor & DRD3 & Ser9Gly (rs6280) & 3 (32 studies) & $\begin{array}{l}1.33 \text { (Lerer et al, 2003) } \\
1.17 \text { (Bakker et al, 2006) } \\
1.16 \text { (Tsai et al, 2010) }\end{array}$ \\
\hline & $\begin{array}{l}\text { Catechol- } 0 \text { - } \\
\text { methyltransferase }\end{array}$ & COMT & Val18Met (rs4680) & 1 (5 studies) & 1.19 (Bakker et al, 2008) \\
\hline Serotonin $(5-\mathrm{HT})$ & $5-\mathrm{HT}_{2 \mathrm{~A}}$ receptor & HTR2A & T102C (rs6313) & 1 (6 studies) & 1.64 (Lerer et al, 2005) \\
\hline $\begin{array}{l}\text { Developmental/plasticity } \\
\text { factors }\end{array}$ & $\begin{array}{l}\text { Heparan sulphate } \\
\text { proteoglycan } 2\end{array}$ & HSPG2 & rs2445142 & 0 (3 studies) & $\begin{array}{l}\text { Nominal (Syu et al, 2010; Greenbaum et al, 2012; } \\
\text { Bakker et al, 2012) }\end{array}$ \\
\hline \multirow[t]{2}{*}{ CYP isoenzymes } & Cytochrome P450 2D6 & CYP2D6 & $\begin{array}{l}\text { Polymorphisms various: } \\
{ }^{*} 1{ }^{*} 2{ }^{*} 3 * 4{ }^{*} 5{ }^{*} 6, \\
{ }^{*} 6 \mathrm{~B},{ }^{*} 10,{ }^{*} 10 \mathrm{~B}, \\
{ }^{*} 17,{ }^{*} 29,{ }^{*} 35,{ }^{*} 41, \\
{ }^{*} 43,{ }^{*} 106,{ }^{*} 1 \mathrm{xn}, \\
{ }^{*} 2 \mathrm{xn}\end{array}$ & 0 (6 studies) & $\begin{array}{l}3 \text { non-significant (Tsai et al, 2010; Jovanovic } \\
\text { et al, 2010; Tyren et al, 2015) } \\
2 \text { marginally significant (Locatelli et al, 2010; } \\
\quad \text { Gasso et al, 2013, 2014) } \\
1 \text { significant - for increased metabolic status } \\
\text { (Koola et al, 2014) }\end{array}$ \\
\hline & & & $\begin{array}{l}\text { Genotype: higher tardive } \\
\text { dyskinesia ratings in } \\
\text { wt/mut } v \text {. wt/wt; } \\
\text { higher tardive } \\
\text { dyskinesia ratings in } \\
\text { mut/mut + wt/mut } \\
\text { v. wt/wt }\end{array}$ & $\begin{array}{l}1 \text { (7 prospective } \\
\text { studies) }\end{array}$ & $\begin{array}{l}2.08 \text { (Fleeman 2010) } \\
1.83 \text { (Fleeman 2010) }\end{array}$ \\
\hline
\end{tabular}

a. The references cited in this table can be found in Owens (2014).SNP, single-nucleotide polymorphism; mut, mutated allele; wt, wild-type allele.Source: Owens (2014). 
BOX 6 Serious medical adverse outcomes of tardive dyskinesia

Trauma
- Falls
- Fractures
- Myoglobinuria
- Renal failure
Overactivity
- Weight loss
- Cachexia
- Lingual hypertrophy
Dysphagia
- Choking
- Inhalation
Respiration
- Stridor
- Speech impairment
Possible death

This is a fledgling literature containing major teething problems, the most obvious of which relate to imprecise clinical characterisation of movement types, generalisation (assuming a single causative mechanism for every presentation) and, most damning of all, serious under-powering.

\section{Course and outcome}

Following emergence, tardive dyskinesia tends to plateau in severity, usually over weeks. Although progression by extension may occur, once stable, progression by severity is uncommon.

There has never been unanimity on the potential for reversibility (Gardos 1980). One problem in addressing this is whether, in an iatrogenic disorder secondary to necessary long-term treatment, reversibility refers to what happens when the drug is stopped or when it is maintained.

Evidence suggests that, on cessation of an antipsychotic, reversibility can occur but figures vary - from 33\% after 2 years (Kane 1986) to only $12 \%$ over an average of 6.7 years (Kang 1986). Such variability relates to types of disorder (e.g. orofacial versus peripheral, especially dystonia) and durations of drug exposure and movement disorder. Recently, Zutshi et al (2014) reported very low rates of spontaneous reversibility: $2.8 \%$ over an average of 4.3 years. The paediatric literature strongly suggests that reversibility on antipsychotic cessation is the rule (Campbell 1988), whereas in working-age adults, it is much less predictable and in the elderly it is probably not likely (Gardos 1983). Age, therefore, is the crucial factor.

Nonetheless, in patients who remain on medication long-term (up to 10 years), the incidence of new cases tends to be offset by cases in whom disorder ameliorates (Gardos 1994). Whether this represents genuine resolution or suppression is unclear but age-related pharmacokinetic and other changes favour the latter.

Tardive dyskinesia can be socially stigmatising and debilitating. Importantly, its physical outcomes can be highly negative (Box 6), with the suggestion of a 1.5- to 2.5-fold increase in mortality risk (Chong 2009; Dean 2009).

This is not a condition whose neglect, in research or clinical terms, is justified.

\section{REFERENCES}

Adityanjee, Aderibigbe YA, Chowdary VC, et al (1999) The current status of tardive dystonia. Biological Psychiatry, 45: 715-30.

Alexopoulos GS (1979) Lack of complaints in schizophrenics with tardive dyskinesia. Journal of Nervous and Mental Disease, 167: 125-7.

Aquino CCH, Lang AE (2014) Tardive dyskinesia syndromes: current concepts. Parkinsonism and Related Disorders, 20(suppl 1): S113-7.

Ayd FJ (1967) Persistent dyskinesia: a neurologic complication of major tranquillisers. Medical Science, 18: 32-40.

Barnes TRE, Braude WM (1985) Akathisia variants and tardive dyskinesia. Archives of General Psychiatry, 42: 874-8.

Branchey M, Branchey L (1984) Patterns of psychotropic drug use and tardive dyskinesia. Journal of Clinical Psychopharmacology, 4: 41-5.

Campbell M, Adams P, Perry R, et al (1988) Tardive and withdrawal dyskinesia in autistic children: a prospective study. Psychopharmacology Bulletin, 24: 251-5.

Carbon M, Hsieh C-H, Kane JM, et al (2017) Tardive dyskinesia prevalence in the period of second-generation antipsychotic use: a meta-analysis. Journal of Clinical Psychiatry, 78: e264-78.

Chakos MH, Alvir JMJ, Woerner MG, et al (1996) Incidence and correlates of tardive dyskinesia in first episode of schizophrenia. Archives of General Psychiatry, 53: 313-9.

Chong S-A, Tay JAM, Subramaniam M, et al (2009) Mortality rates among patients with schizophrenia and tardive dyskinesia. Journal of Clinical Psychopharmacology, 29: 5-8.

Chouinard G, Jones BD (1979) Early onset of tardive dyskinesia: case report. American Journal of Psychiatry, 136: 1323-4.

Dean CE, Thuras PD (2009) Mortality and tardive dyskinesia: Iong-term study using the US National Death Index. British Journal of Psychiatry, 194: 360-4.

DeVeaugh-Geiss J (1982) Prediction and prevention of tardive dyskinesia. In Tardive Dyskinesia and Related Involuntary Movement Disorders (ed J DeVeaugh-Geiss): 161-6. John Wright.

Dufresne RL, Wagner RL (1988) Antipsychotic-withdrawal akathisia v. antipsychotic-induced akathisia: further evidence for the existence of tardive akathisia. Journal of Clinical Psychiatry, 49: 435-8.

Dure LS, DeWolfe J (2006) Treatment of tics. Advances in Neurology, 99 : 191-6.

Edwards MJ, Lang AE, Bhatia P (2012) Stereotypies: a critical appraisal and suggestion of a clinically useful definition. Movement Disorders, 27: 179-85.

Faurbye A, Rasch PJ, Peterson PB, et al (1964) Neurological symptoms in pharmacotherapy of psychoses. Acta Psychiatrica Scandinavica, 40: 10-27.
MCO answers

$1 \mathrm{~d} 2 \mathrm{~d} 3$ e 4 a 5 e 
Fleeman F, McLeod C, Bagust A et al (2010) The clinical effectiveness and cost-effectiveness of testing for cytochrome P450 polymorphisms in patients with schizophrenia treated with antipsychotics: a systematic review and economic evaluation. Health Technology Assessment, 14(3): $1-157$.

Frei K, Truong DD, Fahn S, et al (2018) The nosology of tardive syndromes. Journal of the Neurological Sciences, 389: 10-6.

Gardos G, Cole JO (1980) Overview: public health issues in tardive dyskinesia. American Journal of Psychiatry, 137: 776-81.

Gardos G, Cole J0 (1983) The prognosis of tardive dyskinesia. Journal of Clinical Psychiatry, 44: 177-179.

Gardos GE, Casey DE (1984) Tardive Dyskinesia and Affective Disorders. American Psychiatric Press.

Gardos GE, Casey DE, Cole JO, et al (1994) Ten year outcome of tardive dyskinesia. American Journal of Psychiatry, 151: 836-41.

Glazer WM, Morgenstern H, Neidzwiecki D, et al (1988) Heterogeneity of tardive dyskinesia: a multivariate analysis. British Journal of Psychiatry 152: 253-9.

Glazer WM, Morgenstern H, Doucette JT (1993) Predicting the long-term risk of tardive dyskinesia in outpatients maintained on neuroleptic medications. Journal of Clinical Psychiatry, 54: 133-9.

Gureje 0 (1989) The significance of subtyping tardive dyskinesia: a study of prevalence and associated factors. Psychological Medicine, 19: 121-8.

Jeste DV, Potkin SG, Sinha S, et al (1979) Tardive dyskinesia: reversible and persistent. Archives of General Psychiatry, 36: 585-90.

Jeste DV, Caligiuri MP, Paulson JS, et al (1995) Risk of tardive dyskinesia in older patients: a prospective longitudinal study of 266 patients. Archives of General Psychiatry, 52: 756-65

Jeste DV (2000) Tardive dyskinesia in older patients. Journal of Clinical Psychiatry, 61(suppl 4): 27-34.

Kane JM, Woerner MG, Weinhold P, et al (1982) A prospective study of tardive dyskinesia development: preliminary results. Journal of Clinical Psychopharmacology, 2: 345-9

Kane JM, Woerner MG, Borenstein M, et al (1986) Integrating incidence and prevalence of tardive dyskinesia. Psychopharmacology Bulletin, 22 254-8.

Kane JM, Woerner MG, Lieberman JA (1988) Epidemiological aspects of tardive dyskinesia. Encephale, 14: 191-4.

Kang UJ, Burke RE, Fahn S (1986) Natural history and treatment of tardive dystonia. Movement Disorders, 1: 193-208.

Kidger T, Barnes TRE, Trauer T, et al (1980) Subsyndromes of tardive dyskinesia. Psychological Medicine, 10: 513-20.

Koller W (1983) Edentulous orodyskinesia. Annals of Neurology, 13: 97-9.

Kuo SH, Jankovic J (2008) Tardive gait. Clinical Neurology and Neurosurgery, 110: 198-201.

MacNeil RR, Muller DJ (2016) Genetics of common antipsychotic-induced adverse effects. Molecular Neuropsychiatry, 2: 61-78.

Marsden CD, Tarsy D, Baldessarini RJ (1975) Spontaneous and drug induced movement disorders in psychotic patients. In Psychiatric Aspects of Neurological Disease) (eds DF Benson, D Blummer): 219-66. Grune and Stratton.

Marsden CD, Mindham RHS, Mackay AVP (1986) Extrapyramidal movement disorders produced by antipsychotic drugs. In The Psychopharmacology and Drug Treatment of Schizophrenia) (eds PB Bradley, SR Hirsch): 340-402. Oxford University Press.

McCreadie RG, Thara R, Kamath S, et al (1996) Abnormal movements in never-medicated Indian patients with schizophrenia. British Journal of Psychiatry, 168: 221-6.

McPherson R Collis R (1992) Tardive dyskinesia: patients' lack of awareness of movement disorder. British Journal of Psychiatry, 160: $110-2$
Melamed E, Achiron A, Shapira A, et al (1991) Persistent and progressive parkinsonism after discontinuation of chronic neuroleptic therapy: an additional tardive syndrome. Clinical Neuropharmacology, 14: 273-8.

Morgenstern H, Glazer WM (1993) Identifying risk factors for tardive dyskinesia among long-term outpatients maintained with neuroleptic medications. Archives of General Psychiatry, 50: 723-33.

Munetz MR, Cornes CL (1982) Distinguishing akathisia and tardive dyskinesia: a review of the literature. Journal of Clinical Psychopharmacology, 3 $343-50$

Muscettola G, Pampallona S, Barbato G, et al (1993) Persistent tardive dyskinesia: demographic and pharmacological risk factors. Acta Psychiatrica Scandinavica, 87: 29-36.

Owens DGC, Johnstone EC, Frith CD (1982) Spontaneous involuntary disorders of movement: their prevalence, severity and distribution in chronic schizophrenics with and without treatment with neuroleptics. Archives of General Psychiatry, 39: 452-61.

Owens DGC (2014) A Guide to the Extrapyramidal Side-Effects of Antipsychotic Drugs (2nd edn). Cambridge University Press

Paulson GW, Caligiuri MP, Palmer B, et al (1996) Risk factors for orofacia and limb-truncal tardive dyskinesia in older patients: a prospective, longitudinal study. Psychopharmacology, 123: 307-14

Ridley R (1994) The psychology of perseverative and stereotyped behaviour. Progress in Neurobiology, 44: 221-31.

Ryu S, Yoo JH, Kim JH, et al (2015) Tardive dyskinesia and tardive dystonia with second-generation antipsychotics in non-elderly schizophrenic patients unexposed to first-generation antipsychotics: a cross-sectional and retrospective study. Journal of Clinical Psychopharmacology, 35: 13-21.

Sandyk R, Kay SR, Awerbuch Gl (1993) Subjective awareness of abnormal movements in schizophrenia. International Journal of Neuroscience, 69 : $1-20$.

Schonecker M (1957) Ein eigentumliches Syndrom im ovalen Bereich bei Megaphen Applikation. Nervenarzt, 28: 35-42.

Schooler NR, Kane JM (1982) Research diagnoses for tardive dyskinesia. Archives of General Psychiatry, 39: 486-7

Sigwald J, Bouttier D, Raymondeaud C, et al (1959) Quatre cas de dyskinesie facio-bucco-linguo-masticatrice à evolution prolongée secondaire à un traitment par les neuroleptiques. Revue Neurologique, 100: 751-5.

Tarsy D, Baldessarini RJ (2006) The epidemiology of tardive dyskinesia: is risk declining with modern antipsychotics? Movement Disorders, 21: 589-98.

Tenback DE, van Harten PN, Schloof CJ, et al (2006) Evidence that early extrapyramidal symptoms predict later tardive dyskinesia: a prospective analysis of 10000 patients in the European Schizophrenia Outpatient Health Outcomes (SOHO) Study. American Journal of Psychiatry, 163: $1438-40$.

Uhrbrand L, Faurbye A (1960) Reversible and irreversible dyskinesia after treatment with perphenazine, chlorpromazine, reserpine and ECT. Psychopharmacologia, 1: 408-18.

Ure RJ, Dhanju S, Lang AE, et al (2016) Unusual tremor syndromes: know in order to recognise. Journal of Neurology, Neurosurgery and Psychiatry, 87: 1191-203.

van Harten PN, Hoek HW, Matroos GE, et al (1998) Intermittent neuroleptic treatment and risk for tardive dyskinesia: Curaçao Extrapyramida Syndromes Study III. American Journal of Psychiatry, 155: 565-567.

Woerner MG, Kane JM, Lieberman JA, et al (1991) The prevalence of tardive dyskinesia. Journal of Clinical Psychopharmacology, 11: 34-42.

Woerner MG, Alvir JMJ, Saltz BL, et al (1998) Prospective study of tardive dyskinesia in the elderly: rates and risk factors. American Journal of Psychiatry, 155: 1521-8.

Zutshi D, Cloud LJ, Factor SA (2014) Tardive syndromes are rarely reversible and discontinuing dopamine receptor blocking agents: experience from a university-based movement disorders clinic. Tremor and Other Hyperkinetic Movements, 4: 266. 
MCQs

Select the single best option for each question stem

1 With regard to the clinical features of tardive dyskinesia:

a $80 \%$ of patients have choreoathetoid-type perioral movements

b internal voluntary muscles are selectively spared

c peripheral tremor at a frequency of $<6 \mathrm{~Hz}$ is characteristic

$d$ the earliest signs are lingual

e withdrawal-emergent disorder is irreversible.

2 Tardive dyskinesia:

a characteristically progresses by severity focally rather than by extension
4 An increased risk of developing tardive dyskinesia is associated with:

b comprises homogeneous phenomenology

c is not seen in children exposed to causative agents

$\mathrm{d}$ is associated with increased mortality risk

$\mathrm{e}$ is deeply troubling to sufferers.

3 The incidence of tardive dyskinesia:

a is gender-specific

$\mathrm{b}$ is greatest in those with organic brain disorders

c is higher in the first decade of antipsychotic exposure

$d$ is inversely proportionate to age

$\mathrm{e}$ is non-linearly related to duration of antipsychotic exposure. a antipsychotic potency

b cumulative antipsychotic exposure

c drug-free periods longer than 2 years

d high antipsychotic blood levels

e use of two or more antipsychotics concurrently.

5 Genetic predisposition to tardive dyskinesia is suggested in replicated associations with polymorphisms in:

a $B D N F$ (brain-derived neurotropic factor gene)

b CNR1 (CB1 cannabinoid receptor gene)

c CYP $1 A 2$ (cytochrome P450 1A2 gene)

d DRD4 (dopamine $\mathrm{D}_{4}$ receptor gene)

e HTR2A (5- $\mathrm{HT}_{2 \mathrm{~A}}$ receptor gene). 